\title{
Sustainable development of society and a city based on safe infrastructure facilities
}

\author{
Dmitry Gura ${ }^{1}$, Sergei Samarin ${ }^{1}$, Daria Bespiatchuk ${ }^{1}$, Nafset Khusht $^{1}$, and Saida Pshidatok ${ }^{2}$ \\ ${ }^{1}$ Kuban State Technological University, Moskovskaya Str., 2, 350072Krasnodar, Russia \\ ${ }^{2}$ Kuban State Agrarian University, Kalinina Str., 13, 350044Krasnodar, Russia
}

\begin{abstract}
The objective of the research is to analyze the state and level of safety of infrastructure facilities within the concept of forming a comfortable urban environment and ensuring sustainable development of urbanized territories on the example of social infrastructure facilities, in particular, educational institutions. The main methods of this scientific work are the analytical method, represented by the collection and processing of data from publicly available sources (Rosstat), and the method of field measurements. The object of the research is educational institutions of the Russian Federation at the stage of the analytical research method, and educational institutions of the city of Krasnodar at the stage of field measurements. In the course of the study, violations related to the safety of infrastructure facilities were identified. There is a need to use monitoring technologies to exclude the human factor. In the meantime, the violations detected during the study of the sustainable development of the city and society, cannot be eliminated.
\end{abstract}

\section{Introduction}

Sustainable development is a process of economic and social change, which aligns resources, investments, scientific and technological progress, personal development and institutional change with each other and strengthens the current and future potential to meet human needs [3].

The main goal of sustainable development is to ensure a high level of quality of life in society. According to statistics, more than half of the world's population lives in cities. According to the results of the All-Russian Population Census for 2010 (the next census is planned for October 2020), the share of the urban population in the Russian Federation is $74 \%$ [4]. Thus, it should be noted that at present the concepts of city and society are inextricably linked and the level of quality of the urban environment and its development also depends on the sustainable development of society.

The urban environment is a set of specific fundamental man-made and natural conditions within the boundaries of a particular settlement, affecting the level and quality of life of people [3].

Infrastructure facilities are one of the most important components of the urban environment. Infrastructure is a set of inextricably linked institutions, enterprises that serve as and provide the basis for the functioning of the system [3]. 
Based on the definition, infrastructure facilities play an important role in the life of an individual and the state in general. Therefore, it is necessary to monitor not only the level of development and quality of infrastructure but also its safety.

Infrastructure objects are divided into multiple subtypes. This article, however, considers only social infrastructure, as there is the largest number of social infrastructure objects within the city, and, accordingly, their influence is quite high on the urban environment and society as a whole [9].

\section{Infrastructure Safety Assessment. Materials and Methods}

The materials for the article are open-source data, primarily statistical indicators of the Federal State Statistics Service of the Russian Federation (Rosstat). The methods are, firstly, collection of information from open sources, and secondly, field studies.

\section{Literature Review}

There is a sufficient number of articles on this topic. For example, Helena Soares in her "Social infrastructure and the preservation of physical capital: Equilibria and transitional" dynamics and Anita Kumari in her "Physical \& social infrastructure in India \& its relationship with economic development" state that the level of quality of social infrastructure is determined not only by the quality of the urban environment, but also the economic development of a particular state. Valerija Rogelj in her "Social infrastructure of Silver Economy: Literature review and Research agenda" says that the average life expectancy of people depends on the safety and quality of infrastructure facilities [10]. Anosova V.A. in "Social infrastructure: its essence and content" mentions that the overall development of the individual depends on the level of development and quality of social infrastructure [1]. Bakhareva O.V. in "Technological innovations in the region: prospects for the security of the regional social infrastructure" argues that not only the development of cities and society, but also the economic situation in the regions depends on the safety of infrastructure [2].

\section{The level of safety of social infrastructure in Russia}

Social infrastructure is understood to mean a set of institutions aimed at meeting personal needs, ensuring life, spiritual and intellectual development of the population [5].

Figure 1 shows specific objects that relate to social infrastructure.

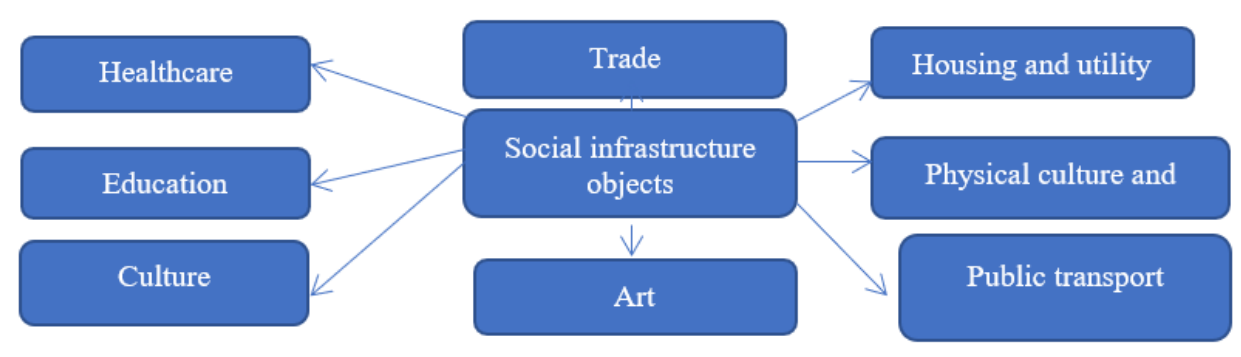

Fig. 1. Objects of social infrastructure

Based on the definition of social infrastructure, we see that its impact on the activities of an individual and society as a whole is quite large. That is why it is necessary to monitor 
the safety of social infrastructure, because social infrastructure facilities accompany us at every step and they have a lot of functions $[8,9]$.

Among the huge number of social infrastructure objects, schools and kindergartens require special attention as objects of daily service, and their role in the life of society and the state is really significant. After all, the state of schools and kindergartens determines the quality of education, and, therefore, the future of any society depends on them $[6,7]$.

As of 2018, there are about 42 thousand schools and 50 thousand kindergartens in the Russian Federation. In terms of the quality of education, the Russian Federation ranks 32nd out of 189 positions. This is a fairly good indicator, despite the quite large number of educational institutions in the Russian Federation. However, we cannot deny problems associated with schools and kindergartens, especially those related to the safety of children. It is especially important to pay attention to the safety associated with the technical condition of the buildings of educational institutions and the safety of their territories.

As for the safety associated with the technical condition of educational institutions, there are 2 points to pay attention to. The first is the rare or complete absence of repairs in schools built 20 or more years ago. This leads to the unfitness of the building for the implementation of educational and educational functions.

According to the Accounts Chamber of the Russian Federation and the Ministry of Science and Higher Education of the Russian Federation, the number of children in schools requiring major repairs is growing. In 2015 there were about 1.8 million people, while in 2016 there were about 1.95 million people.

The situation in kindergartens is almost identical. According to Rosstat data, in 2019, there were 2,434 preschool educational institutions, i.e. $6 \%$ of kindergartens requiring major repairs.

Although, of course, not all schools that require major renovation are old. Thus, a second point arises, which is related to the technical safety of educational institutions, and which needs to be paid attention to. When building new educational institutions, construction companies use cheap and low-quality building materials. This leads to the fact that such institutions require repairs several years after the start of operation. Or it happens that a building that has not yet been put into operation may collapse.

For example, this happened on May 08, 2017. During the construction of a new school in Murino, a suburb of St. Petersburg, the roof and then the second and third floors collapsed. The reasons for the collapse are a mistake in design and savings on building materials.

Having said that, we should note that the situation with the technical security of educational institutions is poor. A considerable number of schools are in need of repair and this is facilitated, firstly, by the long absence of repairs in old schools, and, secondly, by saving on materials during construction and mistakes in designing new schools.

In addition, there are also problems with ensuring the safety of people on the territory of various educational institutions. In the Russian Federation, a lot of regulatory documents have been published regulating the presence of certain objects on the territory of and near educational institutions. But, unfortunately, there are cases when these standards are not observed in practice.

An example of a violated safety of the territory of an educational institution is the situation with school No. 78 in Krasnodar. The problem is that there is a garage cooperative very close to the school building where children of elementary grades study. A general photo of the educational building and garages is shown in Figure 2. 


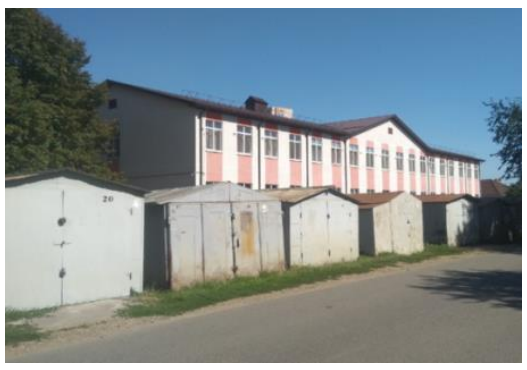

Fig. 2. A photo of the educational building of school No. 78 and the adjacent garage cooperative

According to SNiP 2.07.01-89 "Urban planning. Planning and development of urban and rural settlements", the minimum distance between garages and the school territory is at least 15 meters [5]. To find the actual distance, field measurements were taken. The measurements were taken with a LEICA DISTO D5 laser rangefinder. First, the distance from the school building to the garage cooperative was measured. A photo of the field measurement site is shown in Figure 3.

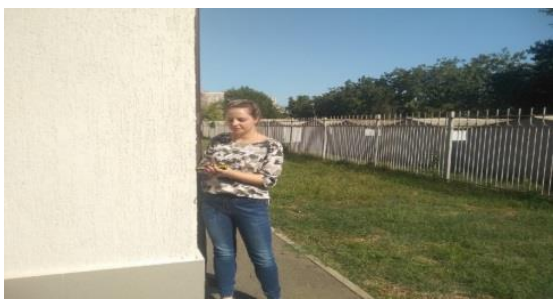

Fig. 3.A photo of field measurements of the distance from the school building to the garages

After that, the distance from the garages to the school fence was measured. A photo of the measurement site is shown in Figure 4.

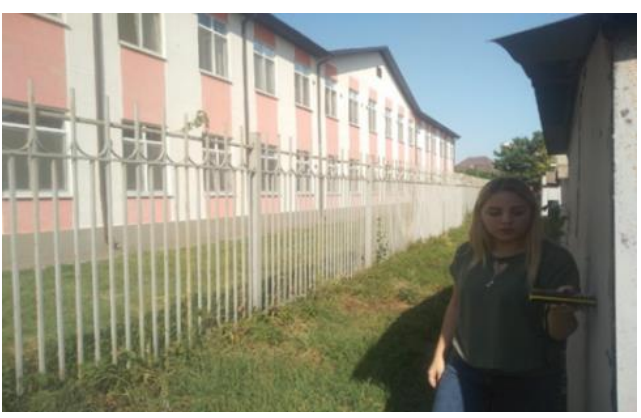

Fig. 4. A photo of field measurements of the distance from the the garages to the school fence

The results of field measurements are shown in Table 1.

Table 1.The results of field measurements of the territory of school No. 78 with a LEICA DISTO D5 laser rangefinder

\begin{tabular}{|l|l|}
\hline Object of measurement & Results of measurements \\
\hline The distance from the school building to the garages & $2.400 \mathrm{~m}$ \\
\hline The distance from the school boundary to the garages & $8.495 \mathrm{~m}$ \\
\hline
\end{tabular}

Field measurements of the territory of school No. 78 found serious violations of SNiP 2.07.01-89. The distance from the border of the school territory to the garages is 6 times 
less than the allowable one. In addition, the distance from the school building to the garage cooperative is almost 2 times less than it should be from the garages to the school territory.

In addition, this circumstance does not meet the safety requirements for educational institutions. The proximity of garages to the school building can be dangerous for elementary school students. Garages are known as a place for storing not only cars, but also various other items, ranging from gasoline to batteries, that can cause a fire. In addition, a garage cooperative can become a place for storing various explosive items, even for terrorist purposes.

Such an attitude towards regulatory documents, especially those concerning educational institutions, is unacceptable. After all, a negligent attitude towards objects located on the territory of or near an institution can lead to tragedy. As, for example, it happened on the territory of kindergarten No.48, in Krasnodar. On September 9, 2019, at 10 a.m., a tree fell on the teacher and two children. As a result, all of them got serious injuries, and one child died.

\section{Results and Discussion}

The analysis of statistical data and the field measurements found the generally unsatisfactory level of safety of the territories of educational institutions, as well as their technical safety. Failure to comply with SNiPs and the lack of monitoring of areas of social infrastructure leads, at best, to violations of regulatory documents, and at worst, to a tragedy with a fatal outcome.

\section{Conclusion}

As mentioned above, infrastructure facilities play one of the key roles in the state of the urban environment and the development of cities in general. The research carried out by the methods of collecting and analyzing statistical data and field measurements revealed a quite low level of safety of infrastructure facilities in Russia. Both technical safety of educational institutions and the safety of their territories are far from ideal. The main reason for all of the above violations is, first of all, human negligence [12].

To ensure the safety of infrastructure facilities, monitoring technologies must be use that can automatically detect violations of various regulations concerning the safety of infrastructure facilities. It is also important that the monitoring technology can detect violations of the norms for the placement and operation of buildings and structures located near socially significant objects.

Such monitoring should be carried out at least every six months. And in case this initiative is supported by the state and local authorities, it will lead to an improvement in the quality of the urban environment and ensure sustainable development of urbanized territories [11].

\section{Acknowledgment}

The reported study was funded by Russian Foundation for Basic Research and Administration of Krasnodar Region of the Russian Federation according to the research project № 19-48-233020 Study of the possibility of using the complex of three-dimensional laser scanning for monitoring and ensuring the safety of infrastructure facilities in the city of Krasnodar and the Krasnodar Territory 


\section{References}

1. V.A.Anosova, V.V. Bondaletov, Proceedings of Ivanovskiye readings, 1(10), 8 (2017)

2. O.V. Bakhareva, A.G. Sulimina, In the collection: Information technologies and modeling of processes in fundamental and applied research, materials of the I International Youth School-Conference, 17 (2016)

3. Great Encyclopedic Dictionary, 2nd (1997)

4. All-Russian population census (2010)

5. SNiP 2.07.01-89 Urban planning, Planning and development of urban and rural settlements

6. A.V. Stetsko, L.V. Zadverniuk, In the collection: Proceedings of sectional sessions of the 60th student scientific-practical conference, PNU, Conference proceedings, 208 (2020)

7. S.T. Torosian, Modern aspects of the economy,7(263), 80 (2019)

8. N.D. Kremlev, Journal of Economic Theory, 15(2), 224 (2018)

9. D. Gura, M. Kuzyakina, I. Gribkova,IOP Conference Series: Earth and Environmental Science, 19 December 2019, 403(1), 012176

10. D.A. Gura, I.G. Markovskii, B.A. Hahuk, S.K. Pshidatok, IOP Conference Series: Materials Science and Engineering, 18 December 2019, 698(4), 044014

11. V. Rogelj, D. Bogataj, Social infrastructure of Silver Economy: IFAC-Papers OnLine, 52(13), 2680 (2019)

12. Yu.V. Efremov, A.V. Zimnitsky, D.Yu. Shulyakov, D.A. Lipilin, Led iSneg, 58(3), 359 (2018) 